\title{
Research on the Arrangement Form of Net Suspenders with Constant Inclination Angle for Steel Box Tied Arch Bridge
}

\author{
Teng $\mathrm{Ma}^{1 *}$, Jingkai Zhao ${ }^{2}$, Dafang $\mathrm{Mei}^{3}$ \\ ${ }^{1}$ Teng Ma, School of Highway, Chang'an Uniersity, xi'an, China \\ ${ }^{2}$ Jingkai Zhao, School of Highway, Chang'an Uniersity, xi' an, China \\ ${ }^{3}$ Dafang Mei, School of Highway, Chang'an Uniersity, xi'an, China
}

\begin{abstract}
In order to explore the rational suspender layout of reticulated suspender steel box tied arch bridge, eight different suspender layout schemes were established by using finite element software Midas civil, taking a real bridge as the background and the constant inclination angle of suspender as the research variable. The structural stress characteristics of vertical suspender and reticulated suspender layout were analyzed and compared. The results show that the bending moment of arch rib and tied beam of reticulated suspender system is smaller, and the stress of arch beam is closer to the ideal state of "arch rib is compressed, tied beam is pulled". The results show that in the range of $60 \sim 90$, the smaller the inclination angle is, the more favorable the stress of the structure is, but the lower the moment reduction efficiency is when the inclination angle of the suspender is less than 60 .
\end{abstract}

\section{Introduction}

The through-type steel box tied arch bridge is composed of arch ribs, tie beams, suspenders, transverse and longitudinal beams, bridge decks, and cross-linked members. This is a typical external statically indeterminate and internal statically indeterminate structure, with clear mechanical concept, low requirement for foundation, small building height, unique landscape effect and excellent environmental coordination, which has been widely used in urban bridges in China ${ }^{[1] \sim[4]}$. The suspender arrangement of the through-type tied arch bridge includes vertical suspender system, Nielsen system and net suspender system. The net suspender system ${ }^{[5]}$ refers to the arrangement of the suspenders arranged obliquely and crossed at least twice, which is essentially Nielsen system with the suspenders arranged densely. This arrangement can effectively reduce the bending moment of arch rib and tie beam, improve the utilization rate of materials, and make the whole structure more

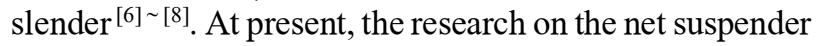
tied arch bridge is more compared with the vertical suspender arrangement. The arch and beam of the net suspender system are closer to the axial stress state, and the vertical stiffness of the structure and the stress amplitude of the suspender is large. The fatigue characteristics of the bridge beam should be mainly calculated in the live load ratio comparison. However, there are few studies on the arrangement of different net suspender systems, and the influence of specific parameters such as the inclined angle and the number of crossing on the static and dynamic characteristics of tied arch bridge lacks research. Here, the inclined angle of the suspender refers to the angle between the projection of the suspender on the lead plane and the horizontal plane.

In this paper, based on the research background of a steel box tied arch bridge with simply supported net suspenders, the corresponding model is established by using Midas civil, and the static and dynamic response laws of the structure under different net suspender arrangements are explored with the constant inclination angle of suspenders as the variable. Then, Considering the convenience of construction [9] and economy [10] and other factors, the reasonable suspender layout form is proposed, which provides a reference for the suspender layout design of this type of bridge.

\section{Project background}

In the construction stage, the superstructure of a bridge is simply supported steel box tied arch. The arch rib is arranged with two arch ribs in the plane and $10^{\circ}$ inclination is set as the basket type. The arch axis has an arch foot spacing of $140 \mathrm{~m}$. The height of projection vector is $23 \mathrm{~m}$, and the ratio of vector to span is $1 / 6.09$, and the linear is parabola layout. There are five cross-girder between the ribs. The length of tie beam is $143.76 \mathrm{~m}$, and the transverse distance of arch axis at arch foot is $21.5 \mathrm{~m}$. The arch rib and tie beam are respectively welded rectangular and parallelogram steel box structures. The bridge deck is a prefabricated reinforced concrete structure, which is connected with the transverse longitudinal beam by shear nails to form a beam grid system. The arch bridge on each side of the main bridge is provided with 32 suspenders with a spacing of $7.5 \mathrm{~m}$, and is arranged with a constant inclination angle. The angle 
between the plane projection and the horizontal plane is $67^{\circ}$. The vertical layout of a simply supported net suspender steel box tied arch bridge is shown in Figure 1.

14376 (Beam length)

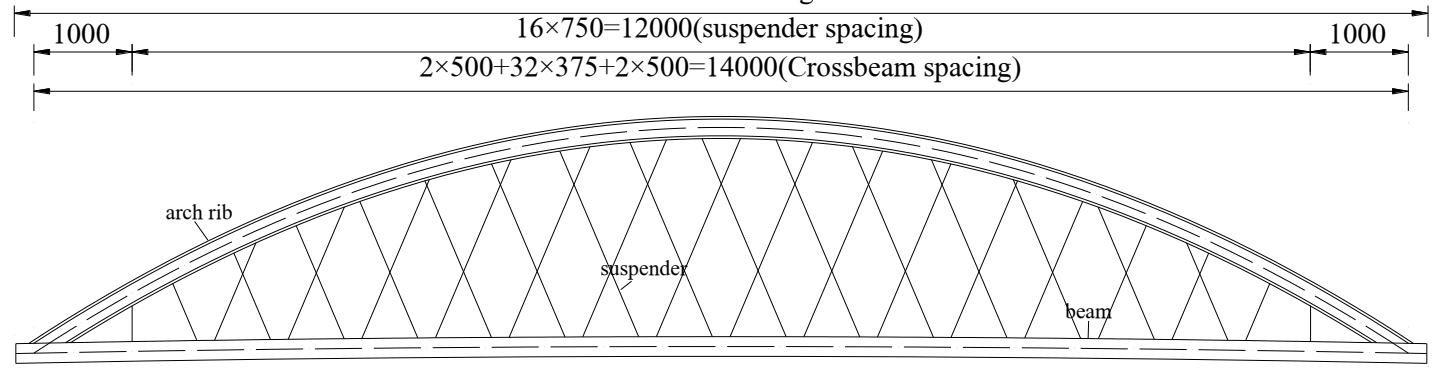

Figure 1. Vertical layout of a simple supported net suspender Steel Box Tied Arch Bridge $(\mathrm{cm})$

\section{Finite element model}

\subsection{Establishment of finite element model}

Midas civil software is used to establish the finite element model of real bridge. The load to be considered is as follows: (1) self weight: the weight of steel structure is $78.5 \mathrm{kn} / \mathrm{m}^{3}$; (2) phase II dead load: including deck pavement and concrete guardrail, the weight of reinforced concrete is $28 \mathrm{kn} / \mathrm{m}^{3}$, and the weight of asphalt concrete is $24 \mathrm{kn} / \mathrm{m}^{3}$; (3) mobile live load: Highway class I and pedestrian load. The finite element model of real bridge is shown in Figure 2.

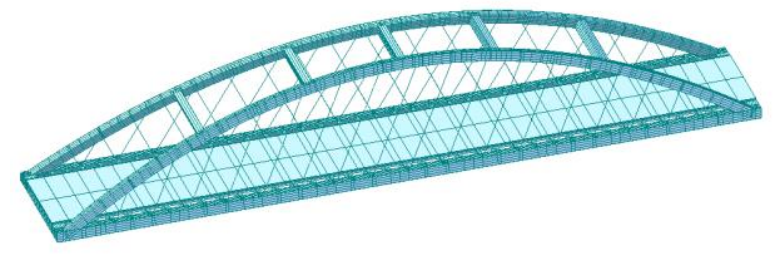

Figure 2. The finite element model of real bridge

\subsection{Parameter range selection}

The range of suspender inclination angle is considered to be $50^{\circ}, 55^{\circ}, 60^{\circ}, 65^{\circ}, 70^{\circ}, 75^{\circ}, 80^{\circ}$ and $90^{\circ}$ (vertical suspender arrangement), and the above eight finite element models with different suspender inclination angles are established to explore the influence of different suspender inclination angles on the static and dynamic characteristics of the structure.

\section{Static characteristics}

\subsection{Internal force analysis under dead load}

The parameters of steel box tied arch, such as rise span ratio, inclination angle of arch rib, rigidity of arch rib and tied beam, are consistent, and the constant inclination angle of suspender is regarded as variable. Under the action of self weight and second stage dead load, the bending moment and axial force of the arch rib and tie beam with 8 different suspender arrangements are shown in Table 1.

Combined with the above results and under the action of self weight and second stage dead load: (1) Different suspender arrangement scheme does not change the internal force distribution form of the structural system. (2) The smaller the inclined angle of suspender is, that is, the denser the suspender is arranged, and the maximum bending moment value of tie beam increases gradually, and the axial force of tie beam decreases gradually, but the numerical difference is very small. When the suspender is arranged at $70^{\circ}$, the maximum bending moment of the arch rib is the smallest, and when the suspender is arranged at $55^{\circ}$, the maximum axial force of the arch rib is the smallest, but the numerical difference is small.

Table 1. Maximum internal force of different suspender arrangement schemes under self weight + second stage dead load

\begin{tabular}{|c|c|c|c|c|c|c|c|c|c|}
\hline The inclined angle of sus & ender & $50^{\circ}$ & $55^{\circ}$ & $60^{\circ}$ & $65^{\circ}$ & $70^{\circ}$ & $75^{\circ}$ & $80^{\circ}$ & $90^{\circ}$ \\
\hline \multirow[b]{2}{*}{ Bending moment (KN.m) } & Arch rib & 8599.9 & 8403.4 & 8294.1 & 8249.5 & 8243.9 & 8264.2 & 8332.4 & 9023.7 \\
\hline & $\begin{array}{c}\text { Tie } \\
\text { beam }\end{array}$ & 6289.4 & 5929.7 & 5614.9 & 5324.6 & 5048.3 & 4782.5 & 4574 & 4027.1 \\
\hline \multirow[b]{2}{*}{ Axial Force (KN) } & Arch rib & 18824.4 & 18788.6 & 18966.6 & 19125.5 & 19265.6 & 19392.1 & 19464.8 & 18005.5 \\
\hline & $\begin{array}{c}\text { Tie } \\
\text { beam }\end{array}$ & 15347 & 15545.4 & 15715.9 & 15868.8 & 16003.9 & 16124.9 & 16193.8 & 14956.5 \\
\hline
\end{tabular}




\subsection{Analysis of influence line of internal force}

The internal force distribution of arch rib and tie beam under concentrated load is studied, and the influence line of internal force of typical section is analyzed. Considering the unfavorable conditions of single arch rib and tie beam, the lane bias load is carried out in the transverse direction of the bridge.

\subsubsection{Comparison of influence lines of internal forces in arch ribs}

Select three typical sections of arch rib arch foot, $1 / 4$ arch rib and arch crown to analyze the internal force influence line of arch rib in different suspender layout schemes, as shown in Figure 4.

The influence line of arch rib shows following rules: (1) For the bending moment of arch foot section, the peak value of influence line of vertical suspender arrangement scheme is between different suspender inclined angle arrangement schemes, and the influence line area is larger than that of different suspender inclined angle arrangement schemes, but the difference is small in general; (2) For the bending moment of the arch crown and $1 / 4$ arch rib section, the peak value and area of the influence line of the vertical suspender arrangement scheme is much larger than that of any suspender inclined angle arrangement scheme, which fully shows that under the concentrated load, the maximum bending moment of the net suspender arrangement scheme is smaller and the stress is more reasonable.

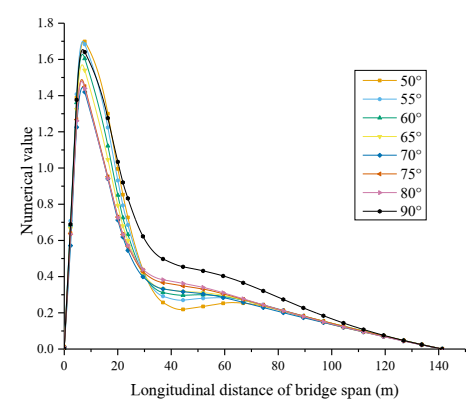

a) Bending moment of arch foot section

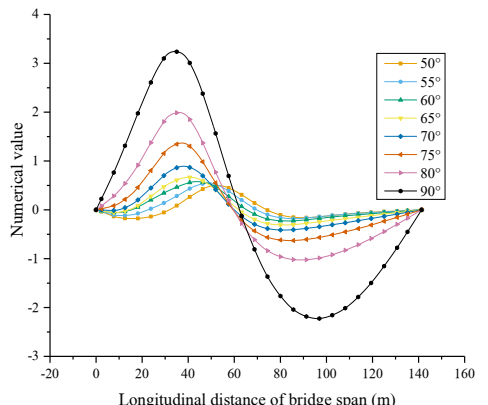

b) Bending moment of $1 / 4$ arch rib section

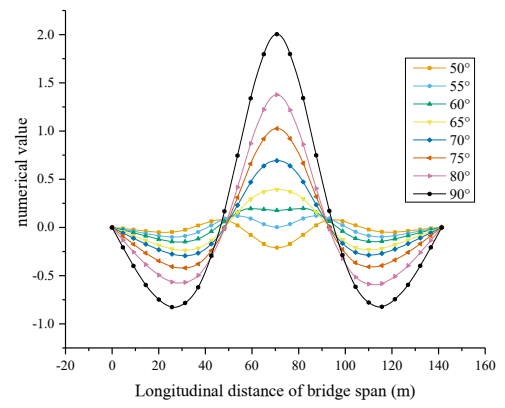

c) Bending moment of vault section

Figure 4. Influence line of internal force of arch rib

\subsubsection{Comparison of influence lines of internal force of tie beam}

Select two typical sections of tie beam 1 / 4 and midspan to analyze the internal force influence line of tie beam in different suspender layout schemes, as shown in Figure 5.

The influence line of tie beam shows following rules: In terms of bending moment, the influence line distribution in the middle span and $1 / 4$ section shows obvious regularity. The peak value and area of the influence line of the vertical suspender arrangement scheme are much larger than that of the mesh suspender arrangement scheme. In the range of the suspender inclination angle of $70^{\circ} \sim 90^{\circ}$, the peak value and area of the influence line decrease with the decrease of the inclination angle, but in the range of the suspender inclination angle of $50^{\circ} \sim 70^{\circ}$, the distribution of the influence line is almost the same.

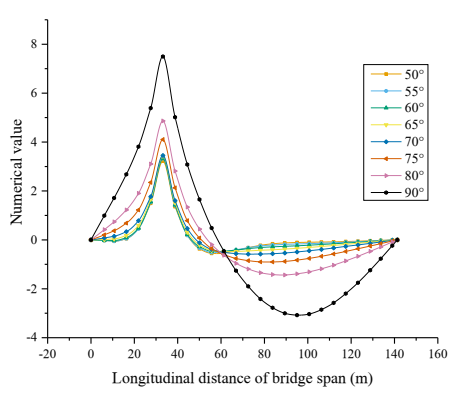

a) $1 / 4$ section bending moment of tie beam

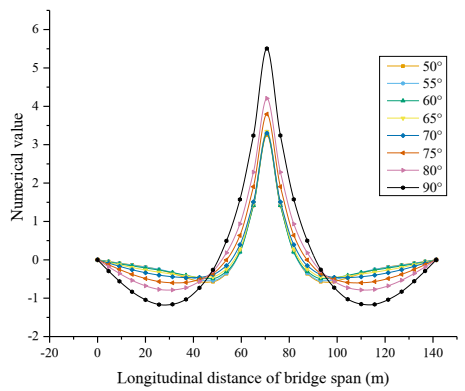

b) Moment of midspan section of tie beam

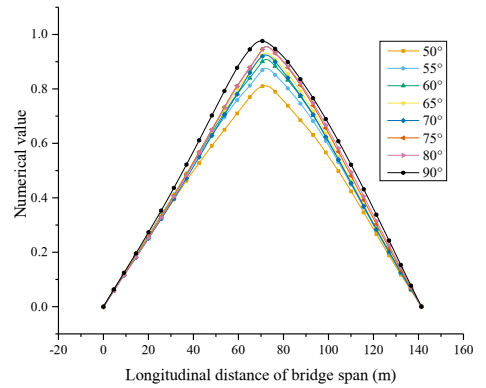

c) Axial force of midspan section of tie beam

Figure 5. Influence line of internal force of tie beam 


\section{Dynamic characteristics}

The analysis of dynamic characteristics shows following rules: (1) The vertical natural frequency and vertical stiffness of the net suspender arrangement schemes are far greater than that of the vertical suspender arrangement scheme. The vertical free vibration frequency of the vertical suspender arrangement is $0.654 \mathrm{HZ}$, and the maximum vertical free vibration frequency is $1.553 \mathrm{hz}$ when the suspender is inclined $60^{\circ}$, which is 2.37 times of the vertical suspender arrangement. (2) In the scheme of net suspender arrangement, it is not that the longer the cable length is, the greater the vertical natural frequency is, but that there is the maximum vertical natural frequency when the suspender is inclined $60^{\circ}$.

\section{Conclusion}

In this paper, the influence of the constant change of the inclined angle of the suspender on the static and dynamic characteristics of the structure is studied, and the following conclusions are obtained:

(1) In practice, the stress of the arch beam is closer to the ideal state of "compression of arch rib and tension of tie beam", which improves the efficiency of section utilization.

(2) For long-span tied arch bridges with a large proportion of dead load, it is recommended to use the layout form of net suspender, and the reasonable range of the suspender's inclination angle is $60^{\circ} \sim 70^{\circ}$.

\section{References}

1. XIAO Ru-cheng. Bridge Structural Systems [M]. Beijing: China Communications Press, 2013.in chines

2. Ichiro Koshi, Steel Bridge, Volume 4 [M]. Beijing: People's Railway Publishing House, 1981.

3. ZHOU De, Ye Mei-xin, Luo Ru-deng. Stress analysis of through steel box tied arch composite bridge on high-speed railway [J]. Journal of Central South University: Natural Science Edition, 2009, 40(5):1457-1464. .in chinese

4. YI Yun-kun. Research on Key Problems in Design Theory of Beam-Arch Composite System [D]. Tongji University, 2007. in chinese

5. Per Tveit.The design of network arches[J].The Structural Engineer, July 1996.

6. LIU Zhao, Lu Zhi-tao. Bridge type study of tied arch structures with vertical and oblique suspenders [J].Journal of Civil Engineering, 2000 , 33(5):63-67. in chinese

7. CHEN Lie, Guo Jian-xun, Li Xiao-zhen. Steel tied arch bridge for high-speed railway [M]. Beijing: China Railway Press, 2010. in chinese

8. LIU Chun-feng, Si Xiu-yong, Jiang Zai-shong, et al. Study on structural system design parameters of steel tied arch bridge [J].World Bridge, 2008(A01):6467. in chinese

9. TANG Hu, Shao Chang-yu, Yan Hai. Study on mechanical and economic performance of tied arch bridge with composite deck [J].Bridge construction, 2019, 49(01):33-38. in chinese

10. XIANG Zhong-fu. Bridge Construction Control Technology [M]. People's Transportation Press, 2001. in chinese 